Tecnología e Innovación

Tecnologia e Inovação

Tecnology and Innovation

\title{
El espacio, futuro de la Fuerza Aérea Colombiana*
}

O espaÇo, Futuro da Força Aérea Colombiana*

The Space, Colombian Air Force Future***

Jonathan Camilo Urbina Carrero

Fuerza Aérea Colombiana. Bogotá, Colombia

\section{CIENCIA Y PODER AÉREO}

ISSN 1909-7050 / E- ISSN 2389-9468 / Volumen 12/ Enero-diciembre de 2017/ Colombia/ Pp. 202-208

Recibido: 22/08/2017

Aprobado: 29/10/2017

Doi: http://dx.doi.org/10.18667/cienciaypoderaereo.572 


\section{Para citar este artículo:}

Urbina Carrero, J., C. (2017). El espacio, Futuro de la Fuerza Aérea Colombiana. Ciencia y Poder Aéreo, 12, 202-208. Doi: http://dx.doi.org/10.18667/cienciaypoderaereo. 572

${ }^{\top}$ Artículo de revisión, producto de la investigación realizada durante el curso básico de ascenso a capitán. Universidad Militar Nueva Granada, proyecto INVING-2108

${ }^{2}$ Artigo de revisão, produto da pesquisa realizada durante o curso básico de promoção ao capitão. Universidade Militar Nova Granada, projeto INV-ING-2108

${ }^{3}$ Review article, product of the research carried out during the basic course of promotion to captain. Military University New Granada, project INV-ING-2108

a Ingeniero Mecánico de la Escuela Militar de Aviación, Piloto Instructor del equipo C-208 Caravan, Teniente de la Fuerza Aérea Colombiana, Grupo Aéreo del Casanare. Yopal, Casanare. Correo electrónico: jcuc82@gmail.com
Resumen: en el presente artículo se estudiarán los satélites artificiales desde su historia, sus características generales, su tamaño, su funcionalidad y su clasificación según diferentes parámetros. Igualmente, se hablará de algunos aspectos relacionados con los tipos de órbita y el procedimiento para el lanzamiento al espacio. Asimismo, se hará un breve resumen de la evolución y avances en países suramericanos, detallando el avance histórico en Colombia liderado por la Fuerza Aérea Colombiana, exaltando su capacidad innovadora de gran impacto en nuestra sociedad.

Palabras clave: satélite, espacio, órbita, evolución, Fuerza Aérea Colombiana.

Resumo: No presente artigo, os satélites artificiais serão estudados a partir de sua história, suas características gerais, seu tamanho, sua funcionalidade e sua classificação de acordo com diferentes parâmetros. Além disso, alguns aspectos relacionados aos tipos de órbita e o procedimento para o lançamento no espaço serão discutidos. Além disso, será elaborado um breve resumo da evolução e do progresso nos países da América do Sul. Finalmente, o avanço histórico na Colômbia com a importância da Força Aérea Colombiana é detalhado, e sua capacidade inovadora de grande impacto em nossa sociedade é exaltada.

Palavras-chave: Satélite, Espaço, órbita, evolução, Força aérea colombiana.

Abstract: This article will review artificial satellites from their historical development, characteristics, size, functionality, and classification according to diverse parameters. It will also show some aspects related to their type of orbit and procedures for launching. Similarly, a summary about evolution and current advances in Latin American countries will be shown. Finally, it is described the historical advance in Colombia and the support of Fuerza Aérea Colombiana (Colombian Air Force), and its innovative capacity of huge impact in Colombian society is highlighted.

Key Words: Satellites, Space, orbit, development, Colombian Air Force. 


\section{Introducción}

El uso de los satélites en la vida diaria es más común de lo que se cree. Diferentes satélites cumplen funciones como suministrar telefonía, televisión, seguimiento y tendencia meteorológica, avances científicos, entre otros; asimismo, un país se desarrolla de una mejor manera a medida que toda su población está comunicada. El hecho que las poblaciones menos favorecidas y alejadas del centro del país tengan comunicación y tecnología a la mano es un punto de evolución, ya que cada vez se evidencia una gran cantidad de avances que son reflejados en la calidad de vida de la población y en el impulso de un país.

El objetivo de este artículo es visualizar el liderazgo que debe tener la Fuerza Aérea Colombiana para generar desarrollo tecnológico espacial, encaminándolo a los nuevos roles que debe cumplir la fuerza. Se toma como como referencia a países como Argentina, que ahora es un país autónomo en el diseño, fabricación y lanzamiento de satélites.

\section{Inicios de la exploración del espacio}

La exploración del espacio comenzó con satélites pequeños debido al tamaño restringido de las plataformas de lanzamiento, lo cual ofrecía información limitada. En 1957 se puso en órbita el primer satélite artificial, Sputnik 1, por la entonces Unión Soviética, la cual fue seguida en 1958 por Estados Unidos con el lanzamiento del Explorer I. Las nuevas tecnologías emergentes, como la micronanotecnología y los microsistemas electromecánicos, hacen que hoy en día los mini y micro satélites tengan unas prestaciones superiores a las plataformas de hace una década y posibiliten el uso de satélites inclusive de menos de 10 kilogramos.

\section{¿Qué es un satélite artificial?}

Un satélite artificial es un objeto tecnológico que simula la actividad de los satélites naturales y orbita alrededor de un cuerpo celeste con el fin de ampliar los estudios acerca del mismo. Los satélites constan de una antena que envía y recibe la información, y de una fuente de alimentación que provee energía para su funcionamiento por medio de baterías o paneles solares.

Estos artefactos son lanzados al espacio por medio de cohetes y tienen una ruta a seguir de acuerdo a la tarea a cumplir. Sus funciones se pueden clasificar en científicas y aplicadas. Dentro de las primeras se encuentran el estudio del espacio y de los planetas, mientras que las funciones aplicadas abarcan observación meteorológica, telecomunicaciones, espionaje militar, etc.

En términos generales y prácticos, los satélites artificiales se pueden clasificar según su trayectoria, tamaño y funcionalidad. A continuación, se detallarán cada una de estas categorías.

\section{Trayectoria}

Los dos tipos más comunes son:

- Geoestacionarios: corresponden a los que se mueven de este a oeste por encima de la línea del Ecuador, es decir, siguen la dirección y velocidad de la rotación terrestre.

- Polares: son aquellos que viajan de polo a polo, en dirección norte-sur.

\section{Tamaño}

En su artículo Nano/Microsatellite Market Assessment, Buchen (2014) explica que los satélites pequeños son hechos en un tamaño estándar, el cual consiste en un cubo de $10 \times 10 \times 10 \mathrm{~cm}$ llamado el CubeSat. Estos son clasificados en diferentes tipos, los cuales se describen a continuación:

\begin{tabular}{l|l|}
\multicolumn{1}{c}{ Satellite Class } & \multicolumn{1}{c}{ Mass Range } \\
\hline Femtosatellite & $10-100 \mathrm{~g}$ \\
\hline Picosatellite & $<1 \mathrm{Kg}$ \\
\hline Nanosatellite & $1-10 \mathrm{~kg}$ \\
\hline Scope of this study & $1-50 \mathrm{~kg}$ \\
\hline Microsatelliete & $10-100 \mathrm{~kg}$ \\
\hline Small Satellite & $100-500 \mathrm{~kg}$ \\
\hline Fuente: Buchen (2014). & \\
\hline
\end{tabular}

\section{Funcionalidad}

Los más comúnmente usados son:

- Satélites de navegación: su mayor ejemplo es el GPS (Global Positioning System). Están conformados por 24 satélites que orbitan a una altitud de $20000 \mathrm{~km}$.

- Satélites de comunicación: suministran la señal de televisión, internet y teléfono.

- Satélites meteorológicos: realizan pronósticos meteorológicos más precisos. Se utilizan en órbita baja y geoestacionaria.

- Satélites de observación: toman imágenes de la tierra y están en órbita baja. 
- Satélites astronómicos: monitorean el espacio y proporcionan imágenes nítidas de estrellas y galaxias distantes.

- Estación internacional del espacio: es un laboratorio y centro de investigación espacial que agrupa los conocimientos científicos de 16 naciones.

\section{Altitudes y órbitas de los satélites}

La altitud de un satélite se elige de acuerdo a la finalidad para la que fue creado, como se describe a continuación:

- Órbita baja (Low Earth Orbit - LEO): de 200 a 2000 km, su tiempo de una órbita es de 90 minutos.

- Órbita media (Medium Earth Orbit - MEO): la mayoría de estos satélites están a 20000 km y su tiempo para una órbita es de 12 horas.

- Órbita geoestacionaria (Geostationary orbit GEO): de 36000 km y más. El tiempo de una órbita es de 24 horas.

\section{Lanzamiento de los satélites}

Para poder llevar un satélite a órbita se requiere de un cohete espacial o cohete portador que lo lleve como carga desde la superficie de la tierra a órbitas alrededor de la misma. El cohete se basa en la tercera ley de Newton (ley de la acción y reacción), según la cual toda acción corresponde a una reacción con la misma intensidad, misma dirección y sentido contrario. Este cohete genera un empuje para propulsarse a reacción y tiene ciertas etapas con las cuales logra ir desintegrándose hasta finalmente soltar el satélite en la órbita deseada.

Muchas bases de lanzamiento son cercanas a la línea del Ecuador ya que es el punto más lejano del centro de la tierra, y mientras más lejos esté un objeto del centro de la tierra, mayor velocidad tiene. La Tierra gira sobre si misma del oeste al este; por tal motivo, puede aprovecharse la velocidad de rotación de la base de lanzamiento lanzando el satélite en la misma dirección. El hecho que un cohete requiera menos velocidad para ser enviado al espacio es de gran importancia, ya que ello se traduce en menor peso, menor consumo de combustible y menor costo. Un satélite en órbita polar no recibe la misma ayuda del impulso de la tierra, por lo que requerirá más energía para alcanzar la misma altitud.

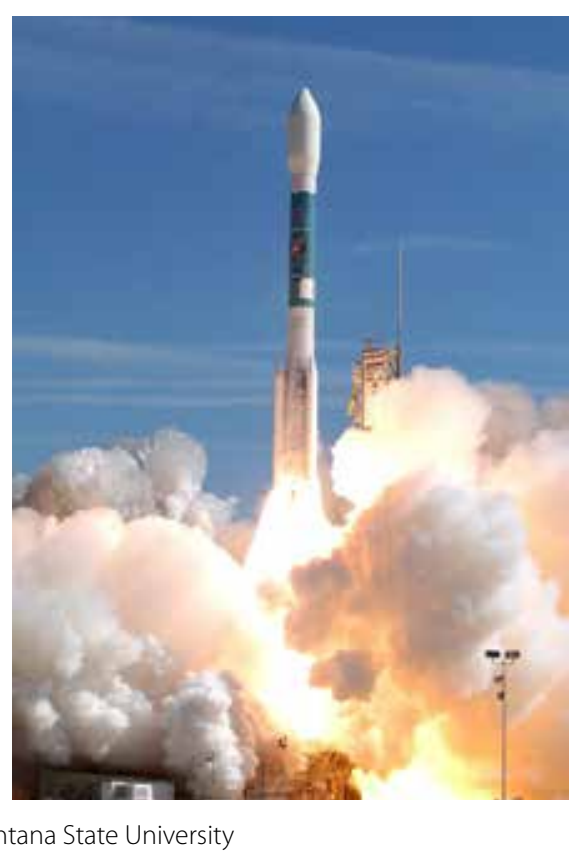

¿Cómo está América del sur en el tema espacial?

La inversión en un programa satelital significa desarrollo tecnológico y soberanía, esta última entendida como la capacidad de un estado de decidir en materia de seguridad y comunicaciones sin la intervención de empresas multinacionales o gobiernos extranjeros. Además, es un impulso a la actividad científica que puede ser aprovechada como un nuevo sector generador de recursos, lo que a la larga tiene un rendimiento económico superior.

Brasil fue el primer país latinoamericano que puso en órbita un satélite en el año 1985, llamado BrasilSat-A1. En la actualidad cuenta con ocho satélites que se encargan de actividades como la investigación, la defensa y las telecomunicaciones.

Chile, por su parte, lanzó su primer satélite en 1995 bajo el programa de transferencia de tecnológica FASat (Fuerza Aérea Satellite), el cual consistió en una alianza entre la Fuerza Aérea de Chile (FACh) y la empresa británica Surrey Satellite Technology Ltd (SSTL). Este programa incluyó la formación de ingenieros chilenos en SSTL para operar la Estación de Control de Misión (ECM-Santiago) en Chile. El primer satélite se llamó FASat-Alfa, el cual fue fallido debido a que no se separó del satélite que lo transportaba por una inconsistencia en su diseño.

El FASat-Bravo se lanzó con éxito en 1998 y ya no se encuentra en uso. El "FASat-Charlie" es el tercer satélite chileno en órbita y el segundo exitoso, también llamado proyecto SSOT (Sistema Satelital de Observación Terrestre). Este satélite tiene su origen en el esfuerzo e iniciativa de un 
CIENCIA Y PODER AÉREO | ISSN 1909-7050 | E-ISSN 2389-9468 | Vol. 12 | Ene - Dic 2017 | Escuela de Postgrados de la Fuerza Aérea Colombiana | pp 202-208

grupo de académicos liderados por la Universidad de Concepción y la FACh, que en conjunto lograron posicionar la necesidad de contar con una capacidad espacial propia de observación remota de la tierra con fines de defensa y de desarrollo del país. El satélite fue lanzado en diciembre de 2011 y actualmente se encuentra en órbita; la proyección es sustituirlo con el satélite Suchai, de fabricación chilena, el cual se lanzará en 2017.

Argentina puso en órbita su primer satélite en 1990, el Lusat I, proyecto de origen no gubernamental construido por radioaficionados de la época. El segundo fue puesto en 1996, Victor-1, diseñado y construido por el Centro de Investigaciones Aplicadas del Instituto Universitario Aeronáutico de Córdoba. Después de esto, el país posicionó otros seis satélites en órbita. El ArSat-1 fue lanzado en el 2014 como un proyecto totalmente nacional de siete años de fabricación, y que convirtió a Argentina en el octavo país del mundo en dominar este tipo de tecnología, detrás de Estados Unidos, Rusia, China, Japón, Israel, India y la Unión Europea.

Ecuador lanzó al espacio en el 2013 su primer satélite, Pegaso, fabricado en el mismo país y lanzado en China. Este sufrió un choque con basura espacial y fue dado por perdido. Ese mismo año lanzaron el satélite Kryasor desde Rusia con resultados satisfactorios hasta el día de hoy.

Bolivia realizó una inversión de 300 millones de dólares en un satélite llamado Tupac Katari, fabricado por China. Se puso en órbita desde el 2013 y se le estima una vida útil de 15 años.

Perú lanzó en el año 2013 dos satélites: el PUCP-SAT1 y el Pocket-PUCP. En el 2014 lanzó el CHASQUI 1. Los tres satélites fueron fabricados y puestos en órbita por entidades privadas del Perú. En el 2016, el Estado peruano lanzó su primer satélite SAT-1 fabricado en conjunto con una empresa francesa.

Venezuela puso en órbita su primer satélite de comunicaciones bautizado Simón Bolívar (VeneSat-1) en octubre de 2008. Su objetivo es facilitar a la población el acceso a servicios de televisión, internet, telefonía, entre otros, con una vida útil de 15 años. Adquirió un segundo satélite de observación Ilamado Satélite de Miranda (Vrss-1), el cual fue lanzado en septiembre del 2012; su finalidad es la observación de cultivos y minería ilegal, recursos naturales, desplazamiento de fuerzas militares y actualización de los mapas del país. En octubre de 2017, posicionó un tercer satélite llamado Satélite Antonio José Sucre (Vrss-2), el cual fue lanzado en el centro satelital de Jiuquan en China. Este satélite tendrá una vida útil de 5 años y cumplirá con misio- nes de observación y recepción, aumentando la capacidad de toma de imágenes respecto al satélite Miranda.

Uruguay lanzó su primer satélite en el año 2014, el AntelSat. El satélite trabajó durante 10 meses, al cabo de los cuales se averió por una degradación de sus componentes. Ahora comparte el uso del VeneSat-1, utilizando un $10 \%$ de su capacidad, suficiente para suplir las necesidades.

Paraguay creó la Agencia Paraguaya del Espacio con el objetivo principal de tener su propio satélite para el 2018.

\section{Desarrollo de Colombia en el espacio}

La historia espacial de Colombia inició en 2007 con el Libertad 1, el primer picosatélite colombiano puesto en órbita lanzado desde Kazajstán. El proyecto consistió en un diseño prefabricado llamado CubeSat desarrollado por el ingeniero Robert Twiggs, profesor de la Universidad de Standford (EEUU) bajo el auspicio de Boeing. A este diseño se le incorporaron algunos sistemas periféricos y elementos de construcción colombiana. Su financiación estuvo a cargo de la Universidad Sergio Arboleda. Este dispositivo tiene forma cúbica, con aproximadamente $10 \mathrm{~cm}$ por lado y menos de $1 \mathrm{~kg}$ de peso. Fue catalogado como un picosatélite experimental, y su única función fue emitir una señal de radio con información sobre su estado de funcionamiento, la temperatura de sus partes exteriores y datos sobre sus circuitos. El satélite cumplió su misión por aproximadamente 30 días, tiempo que duraron las baterías; después se convirtió en una pieza más de basura espacial.

La Comisión Colombiana del Espacio (CCE) fue creada en Julio del 2006 con el objetivo principal de lanzar un satélite de comunicaciones Ilamado SatCol-1 en el año 2011; así no se seguirían alquilando los servicios espaciales a operadores extranjeros. Con el fin de dar paso a este proyecto, en el año 2009 se evaluaron los servicios ofrecidos por una empresa rusa y en el 2010 por una entidad china quienes contaban con el servicio de creación y lanzamiento del satélite. Sin embargo, no hubo acuerdo entre las compañías y las condiciones que exigía el Estado y los procesos fueron declarados desiertos.

La secretaría de la CCE fue asumida por la Fuerza Aérea Colombiana en el año 2012 y se anunció el desarrollo de un proyecto para la creación de un nanosatélite de observación, con una vida útil de 2 a 3 años, llamado FacSat-1, el cual pesaría aproximadamente 10 kg y contaría con una cámara para tomar imágenes de la tierra. Sería puesto en órbita en el año 2014. 
Con algún retraso en el tiempo programado debido a la situación social, política y financiera del país, hasta el 2014 se culminó la fabricación del nanosatélite. En el año 2016 se consiguió el apoyo económico para ser puesto en órbita durante el primer trimestre del 2018, por lo que se contrató la empresa GOM SPACE, de origen danés, y se contará con una estación remota que será ubicada en la Escuela Militar de Aviación (Emavi) en Cali.

Actualmente se inicia el proyecto del Facsat-2, la evolución del Facsat-1 y liderado por el Departamento de Investigación, Desarrollo e Innovación (DIDIN) de la Fuerza Aérea Colombiana. Este proyecto busca mejorar la resolución de las imágenes tomadas y planea tener en la EMAVI un laboratorio de ensamblaje de nanosatélites. La fuerza tiene el objetivo de contar con una constelación de seis nanosatelites, iniciando con el Facsat-1, para ser puestos a disposición de la nación y con ello beneficiar a varios sectores socioeconómicos del país diferentes al sector defensa.

Al realizar una comparación a nivel suramericano, Colombia es un país con avance espacial incipiente y con grandes retos. Al evaluar las metas ya trazadas, se hace necesario establecer la proyección del país en el ámbito de la tecnología espacial, con lo cual será posible iniciar con la capacitación acerca del tema y la aplicación práctica de los conocimientos obtenidos, asumiendo los riesgos que este campo de la tecnología confiere. Sólo así podrá decirse que Colombia tiene un lugar en el espacio.

La Fuerza Aérea Colombiana puede optar por agrupar los esfuerzos del Estado, el ámbito académico y las entidades privadas, con el fin de conglomerar los esfuerzos políticos, científicos y económicos respectivamente. Según la revisión bibliográfica, ésta es la vía más viable para lograr el desarrollo de la ciencia espacial en una nación como la colombiana.

Entre los beneficios tangibles al desarrollar la ciencia espacial en nuestro país y lograr posicionar un satélite en órbita están una mayor cobertura de telecomunicaciones, facilidad en las opciones de estudio y mejoraría en el estado de actualidad en las zonas más remotas del territorio nacional. Adicionalmente, se podrá realizar la evaluación de los suelos agrícolas, de los recursos hídricos y zonas en peligro de desertificación; se podrá obtener información sismológica para prevención de desastres, y se tendrán imágenes propias para el sector defensa. Todo ello sin la intervención de un tercero contratado para suplir estas necesidades.

El espacio es el lugar que debe tener la Fuerza Aérea Colombiana del futuro: una fuerza innovadora. La institución debe apostarle a romper paradigmas, a creer en sí misma y a promover un trabajo intersectorial, en conjunto del sector público y privado, con el fin de generar el desarrollo tecnológico del país.

\section{Conclusiones}

La Fuerza Aérea Colombiana debe generar una estrategia para capacitar a su personal en temas como ingeniería mecánica, ingeniería espacial, ingeniería electrónica, física, maestrías, doctorados referentes al estudio del espacio y sus posibles aplicaciones con el fin de generar progreso $y$, con ello, lograr el desarrollo de tecnología para el país.

Se debe formar una conciencia política para que el estado asigne mayores recursos con el fin de desarrollar tecnología espacial en el país y satisfacer nuestras necesidades sin ayuda de terceros, mostrando la importancia de tener una constelación de satélites con la cual toda Colombia podrá estar comunicada y todos sus habitantes comenzaran a educarse y día a día se verá el progreso y la cultura de sus habitantes, direccionándola al desarrollo de la nación.

Se evidencia que Colombia es un país que ha invertido muy poco en el tema espacial, en comparación con algunos países de Suramérica; apenas hasta el año 2018 se espera poner en órbita un satélite con aspiraciones a orbitar de 2 a 3 años. Sin embargo, lo realmente importante es iniciar el camino. La CCE, en conjunto con las universidades y la Fuerza Aérea, deben generar un proyecto visualizando el desarrollo de ciencia y tecnología espacial, para lo cual deben planear correctamente su dinámica de evolución con el fin de lograr el éxito.

La Fuerza Aérea Colombiana debe agrupar los esfuerzos del estado, el ámbito académico y el sector privado para lograr el desarrollo y solucionar problemas sociales que surgen a raíz de la actualidad del país.

Países como Argentina, Chile y Brasil en este momento cuentan con gran desarrollo en el área espacial. Para Colombia sería muy importante generar alianzas con el fin de impulsar su desarrollo de tecnología e implementar métodos utilizados por estados que tuvieron éxito en el lanzamiento de satélites.

Debido a la situación que atraviesa el país, la Fuerza Aérea Colombiana debe liderar el desarrollo tecnológico en el ámbito espacial. Todo su personal debe proyectar una Fuerza desarrollada tecnológicamente, para lo cual debe generarse un plan de desarrollo que piense en diseño, planeación, construcción y aplicación de una infraestructura de última generación para crear cohetes espaciales capaces de transportar cargas y crear satélites que serán puestos en órbita con el fin de cumplir diversas tareas. Lo 
CIENCIA Y PODER AÉREO | ISSN 1909-7050 | E-ISSN 2389-9468 | Vol. 12 | Ene - Dic 2017 | Escuela de Postgrados de la Fuerza Aérea Colombiana | pp $202-208$

anterior con el fin de generar productividad y desarrollo en el país, integrando el sector político y económico para garantizar su funcionamiento y operación.

\section{Referencias}

Buchen, E. (2014). Nano / Microsatellite Market Assessment. SpaceWorks Enterprises. Georgia. Recuperado de http://www. sei.aero/eng/papers/uploads/archive/Small\%20Sat\%20Paper_SSC14-I-3.pdf

Betancourt, M. (2015). Nanotechnology + Small Satellites = Big Returns. Air \& Space Smithsonian. Disponible en: https:// www.airspacemag.com/daily-planet/nanotechnologysmall-satellites-big-returns-180956082/

Fernández, F. (2013). Ciencia y Espacio: Ecuador lanza su primer satélite al espacio. CNN en Español. Disponible en: http:// cnnespanol.cnn.com/2013/04/26/ecuador-lanza-su-primersatelite-al-espacio/

Howell, E. (2017). What is a Satellite? Science \& Astronomy. Disponible en: https://www.space.com/24839-satellites.html

Irigaray, J. (2014). Argentina primer país latinoamericano con satélite propio. El Mundo. Disponible en: http://www.elmundo. es/ciencia/2014/10/17/5440537222601d0a5d8b457b.html

Jiménez, G. (2016). Las aspiraciones espaciales colombianas. Disponible en: http://www.fuerzasmilitares.org/opinion/6852colombia-espaciales.html

McInnes, A. (2013). Artificial Satelites. Science learning hub. Disponible en: https://www.sciencelearn.org.nz/resources/269artificial-satellites

Murcia, J. (2012). Estudio de la trayectoria de un cohete de tres etapas lanzado desde el territorio colombiano (Tesis de maestría). Universidad Nacional de Colombia. Bogotá: Colombia.

Paikowsky, D.; Baram, G.; Israel, I. (2015). Trends in space activities in 2014: The significance of the space activities of governments. Acta Astronautica, 118, 187-198.

Pechiar, M. (2016). La historia del primer satélite uruguayo. Universidad de la República. Disponible en: https://www.fing.edu. uy/noticias/area-de-comunicacion/la-historia-del-primersatelite-uruguayo

Planas, A. (2017). El gobierno de Chile evalúa tres alternativas para reemplazar al Fasat Charlie. Disponible en: http://www.infoespacial.com/latam/2017/04/03/noticia-gobierno-chileevalua-alternativas-reemplazar-fasat-charlie.html

Riebeek, H. (2009). Catalog of Earth Satellite Orbits. Disponible en: https://earthobservatory.nasa.gov/Features/OrbitsCatalog/

Riebeek, H. Planetary Motion: The History of an Idea That Launched the Scientific Revolution. Disponible en: https://earthobservatory.nasa.gov/Features/OrbitsHistory/
Sánchez, A. (2015). Military Technology. Latin America's Space Programmes: Geopolitical Considerations. Military Technology, 43-90.

Sacristán, F. (2005). Satélites de comunicación. Revista Latinoamericana de Comunicación CHASQUI, 91, 4-71.

Shulze-Makuch, D. (2017). A Vision for planetary science in 2050. Air \& Space Smithsonian. Disponible en: https://www. airspacemag.com/daily-planet/vision-planetary-science-2050-180962366/

Thiruvenkatachar, V. (1958). Artificial earth satellites. Defence Science Journal, 8(4), 311-325. 
